\section{Anion-sensitive coated wire electrode based on a hardener in epoxy resin}

\author{
T. Honjo and S. Hata \\ Department of Chemistry, Kanazawa University, \\ Kanazawa 920, Japan
}

\section{Anionen-sensitive Drahtelektrode mit gehärtetem Epoxyharz-Überzug}

It has been found that a copper wire coated with epoxy resin (Luveak-812) hardened with didocenylsuccinic anhydride (Luveak-DDSA, hardener) in the presence of 2,4,6-tri(dimethylaminomethyl) phenol (Luveak-DMP-30, accelerator) and with polyamide (Araldite, hardener) functions effectively as a sensor for anions such as nitrate, chloride, bromide, iodide, perchlorate, and sulfate in the range of $10^{-6}$ to $10^{-1} \mathrm{~mol} / 1$.

\section{Experimental}

The top part $(1-1.5 \mathrm{~cm}$ in length) of a fine copper wire $(1.0 \mathrm{~mm}$ in diameter) of co-axial cable $(7.0 \mathrm{~mm}$ in diameter, $8-10 \mathrm{~cm}$ in length) was coated with epoxy resin hardened with $50 \%$ of Luveak-DDSA in the presence of $2.5 \%$ Luveak-DMP-30 and with $50 \%$ of polyamide each. The electrodes were allowed to stand for $2-3$ days at room temperature $\left(20-25^{\circ} \mathrm{C}\right)$, as previously described $[1-3]$. The remainder of the exposed wire was wrapped tightly with Sealon film (Fuji Photo Film Co., Ltd) in order to prevent direct contact of the metal surface with the test solution. A model M-7 II Hitachi-Horiba $\mathrm{pH}$-meter equipped with a model 2010A Ag/AgCl reference electrode (pinhole type) was used to make the potential measurement. The coated-wire electrode prepared in this manner (Fig. 1) was soaked in deionized water for $20-30 \mathrm{~min}$ before measurement.

This electrode gave potential responses to changes in ion activities of anions such as nitrate, chloride, bromide, iodide, perchlorate, and sulfate when placed in each solution within 1 min. A copper wire electrode coated with a mixture of epoxy resin containing $60 \%$ of hardener such as ethylenediamine, diethylenetriamine, and triethylenetetramine each, gave no potential responses for any anions. The coated-wire electrode can be stored in air and is stable a month or longer. The potential

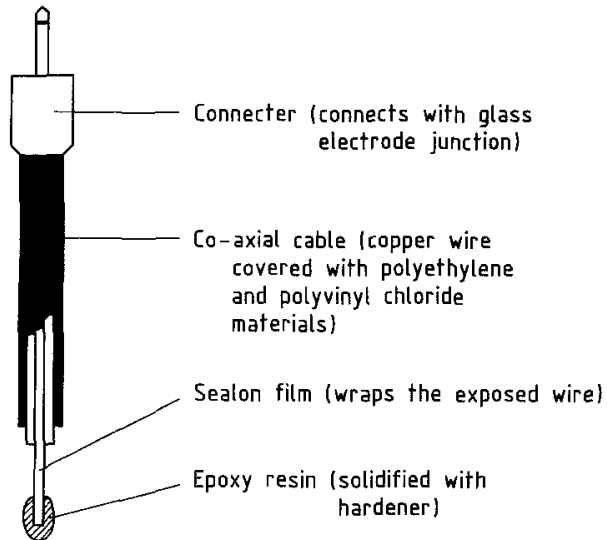

Fig. 1. Anion-sensitive coated wire electrode

of the electrode changes from -100 to $+200 \mathrm{mV}$ in the range of $10^{-6}$ to $10^{-1} \mathrm{~mol}$ anions. The electrode with Luveak-DDSA containing Luveak-DMP-30 gave a somewhat higher potential than that with Araldite. The $\mathrm{pH}$-range for effective use of the electrode was $5-12$, giving a constant potential. The response of the electrode is linear in the range of $10^{-5}$ to $10^{-1} \mathrm{~mol} / 1$ anion, with a nearly Nernstian slope of about $40-70 \mathrm{mV}$ per activity as shown in Table 1.

The potential responses of this electrode were not specific for the anions investigated, however it may be useful as multisensor for these anions.

Acknowledgement. The authors wish to thank Professor $\mathrm{K}$. Terada of Kanazawa University for his helpful advice.

\section{References}

1. Carmack GD, Freiser H (1977) Anal Chem 49:1577

2. Honjo T (1980) Fresenius Z Anal Chem 303:26

3. Lee YK, Park JT, Kim CK, Whang KJ (1986) Anal Chem $58: 2101$

Received September 8, 1987

Table 1. Behaviour of anion-sensitive coated wire electrode based on a hardener in epoxy resin at $20^{\circ} \mathrm{C}$

\begin{tabular}{|c|c|c|c|c|c|c|}
\hline \multirow[t]{2}{*}{ Anion } & \multicolumn{2}{|l|}{$\begin{array}{l}\text { Slope } \\
\mathrm{mV} / \log \mathrm{a}\end{array}$} & \multicolumn{2}{|c|}{$\begin{array}{l}\text { Concentration range } \\
\text { of linear response }(\mathrm{mol} / \mathrm{l})\end{array}$} & \multicolumn{2}{|c|}{$\begin{array}{l}\text { Useful concentration } \\
\text { range }(\mathrm{mol} / \mathrm{l})\end{array}$} \\
\hline & DDSA-DMP & Araldite & DDSA-DMP & Araldite & DDSA-DMP & Araldite \\
\hline Nitrate & 56 & 68 & $10^{-5}-10^{-1}$ & $10^{-4}-10^{-1}$ & $10^{-6}-10^{-1}$ & $10^{-6}-10^{-1}$ \\
\hline Chloride & 56 & 56 & $10^{-4}-10^{-1}$ & $10^{-4}-10^{-1}$ & $10^{-6}-10^{-1}$ & $10^{-6}-10^{-1}$ \\
\hline Bromide & 60 & 62 & $10^{-4}-10^{-1}$ & $10^{-4}-10^{-1}$ & $10^{-6}-10^{-1}$ & $10^{-6}-10^{-1}$ \\
\hline Sulfate & 40 & a & $10^{-3}-10^{-2}$ & a & $10^{-6}-10^{-1}$ & $10^{-6}-10^{-2}$ \\
\hline
\end{tabular}

${ }^{a}$ Linear response was not observed. The selectivity of these electrodes for nitrate generally increased in the order of chloride $<$ bromide $<$ iodide, perchlorate for each foreign ion 